\title{
Surgical plate fixation of multiple rib fractures: a case report
}

\author{
Konstantin Mitev ${ }^{1,2^{*}}$, Dashurie Neziri ${ }^{1}$, Emil Stoicovski ${ }^{1}$ and Zan Mitrev $^{3}$
}

\begin{abstract}
Background: The healthcare system in developing countries is limited; particularly, medical specialties such as emergency and trauma medicine are underdeveloped. Consequently, trauma injuries sustained in traffic accidents result in chronic morbidity more often than similar cases in developed countries. Multiple rib fractures induce significant patient morbidity. Current international guidelines recommend a multidisciplinary, surgery-based treatment approach to achieve optimal clinical benefit.

Case presentation: We admitted a 41-year-old Albanian man to our emergency department following a pedestrianvehicle accident 5 days earlier. He presented with severe upper thoracic pain, chest deformity, dyspnea, tachycardia, subcutaneous emphysema, and hematoma. Chest radiography pointed to hypoventilated lung fields and a minor pleural effusion. Computed tomographic scans indicated displaced fractures of right lateral ribs $5-11$, hyperdensity regions from bone fragments, and pulmonary contusion. The treatment consisted of surgical fixation of ribs 7-10 using titanium reconstruction plates and cortical locking screws. The patient's clinical condition rapidly improved postoperatively. Followup at 6 weeks confirmed a full return to preoperative daily activities and a high quality of life.

Conclusions: In this case report, we present a novel and promising development in the field of trauma medicine in the Republic of Macedonia. Trauma injuries can be treated via advanced multidisciplinary medical care according to international standards, allowing optimal health recovery.
\end{abstract}

Keywords: Multiple rib fractures, Surgical rib fixation, Reconstruction plates, Republic of Macedonia

\section{Background}

The public healthcare system in developing countries struggles to follow international clinical guidelines because of inadequate medical infrastructure, lack of expert medical staff, and limited financial means. Emergency and trauma medicine are limited in developing countries such as the Republic of Macedonia [1, 2]. Consequently, trauma injuries remain a significant source of morbidity and mortality, in contrast to other Western countries [3]. Nevertheless, private healthcare practitioners support the public system and play a substantial role in the advancement of clinical practice in developing countries.

\footnotetext{
* Correspondence: konstantin.mitev@zmc.mk

${ }^{1}$ Department of Orthopedic Surgery, Zan Mitrev Clinic, Skopje, Republic of Macedonia

${ }^{2}$ Faculty of Medical Sciences, University Goce Delchev, Shtip, Republic of Macedonia

Full list of author information is available at the end of the article
}

Blunt thoracic injuries sustained during road accidents frequently result in the fracture of one or more ribs. Rib fractures represent $20-40 \%$ of trauma cases in emergency departments $[4,5]$, encouraging numerous researchers to assess the best practice guidelines. The recommended management of rib fractures has fluctuated over time, from conservative treatments based on external stabilization, analgesia, and respiratory support to internal surgical rib fixation. However, several lines of evidence indicate that surgical fixation complemented with a multidisciplinary bundled care pathway offers superior clinical benefit [6], particularly for patients who have sustained six or more rib fractures $[4,5,7-9]$. This case report describes an advanced multidisciplinary treatment provided by a team of anesthesiologists, trauma surgeons, intensivists, and physiotherapists that is unique to the Southeast Europe region. This case report signifies an imperative advancement in emergency and trauma medicine in the Republic of Macedonia.

(C) The Author(s). 2018 Open Access This article is distributed under the terms of the Creative Commons Attribution 4.0 International License (http://creativecommons.org/licenses/by/4.0/), which permits unrestricted use, distribution, and reproduction in any medium, provided you give appropriate credit to the original author(s) and the source, provide a link to the Creative Commons license, and indicate if changes were made. The Creative Commons Public Domain Dedication waiver (http://creativecommons.org/publicdomain/zero/1.0/) applies to the data made available in this article, unless otherwise stated. 


\section{Case presentation}

We admitted a 41-year-old Albanian man with dyspnea to our emergency department. He was complaining of severe upper thoracic chest pain after being involved in a pedestrian-vehicle traffic accident 5 days earlier. The patient was hit by a car while walking on the pavement, resulting in multiple rib fractures. Initial conservative treatments at another medical institution had failed to alleviate his symptoms. He had had recurrent episodes of fever in the days preceding his admission to our clinic.

The patient, a self-employed business owner, was still in emotional trauma upon his admission to our hospital. His medical history showed no evidence of narcotic addiction, but the patient's family reported that he is a regular smoker and that he consumes above average amounts of alcohol.

Our examinations revealed an elevated blood pressure of 150/90 mmHg, mild tachycardia ( $95-105$ beats/min), a chest deformity, subcutaneous emphysema, hematoma, and a score of 5 on a visual analogue scale (VAS) for pain [10]. From this point on, the patient's pain intensity was assessed every 60 minutes; pain management was performed accordingly via intravenous analgesics because the patient was uncooperative with the epidural anesthesia.

Laboratory evaluations suggested possible liver trauma, indicated by elevated aspartate aminotransferase (AST) of $89 \mathrm{U} / \mathrm{L}$ and alanine aminotransferase (ALT) of $122 \mathrm{U} / \mathrm{L}$, which was excluded by computed tomography. The patient had a normal renal function, Urea and Creatinine levels of $6.9 \mathrm{mmol} / \mathrm{L}$ and $64.4 \mu \mathrm{mol} / \mathrm{L}$, respectively. The patient had normal body temperature $\left(36.6^{\circ} \mathrm{C}\right)$ and white blood cell counts $\left(8.8^{*} 10^{3}\right.$ cells/ $\left.\mu \mathrm{l}\right)$.

We observed no neurological abnormalities. Chest radiography revealed possible fractures of several right lateral ribs, hypoventilated lung fields, and minor pleural effusion. Transthoracic echocardiography showed no other abnormalities. The patient's left ventricular ejection fraction of
$60 \%$ and blood pressure of $120 / 80 \mathrm{mmHg}$ pointed to steady hemodynamics. Computed tomographic scans indicated displaced fractures of right lateral ribs 5-11 (Fig. 1), hyperdensity zones from bone fragments, and pulmonary contusion (Fig. 2).

We opted for general endotracheal anesthesia followed by an anterolateral thoracotomy. The transection was performed below the chest, above the costal margins, through cauterization of the pectoralis, serratus, and intercostal muscles. Four displaced ribs, the seventh through tenth, were stabilized using titanium reconstruction plates and cortical locking screws (small notch titanium reconstruction plates, thickness $3.5 \mathrm{~mm}$, width $8 \mathrm{~mm}$, catalogue number 489245; DePuy Synthes, West Chester, PA, USA). After thoracic drainage, $32 \mathrm{Fr}$, the surgery was terminated via standard closure of the intercostal wound incision and suturing overlying tissue. We transferred the patient to the intensive care unit following the surgery, where he stayed for 48 hours with no significant postoperative complications. Within the first 12 hours, the patient reported a low VAS pain score $(<2)$; as a result, we started with a rehabilitative physical therapy program from this point on. However, the patient experienced significant pain (VAS score of " $6-8$ ") upon mobilization. He was more cooperative at this stage and allowed the placement of an epidural catheter between the fourth and fifth lumbar vertebrae for continuous infusion of bupivacaine $(0.25 \% ; 3-5 \mathrm{ml} / \mathrm{h})$. The epidural analgesia decreased the patient's VAS pain score to 2 . Evaluation of the patient's respiratory function confirmed a gradual recovery and full independence from the respiratory support system 48 hours after surgery (Table 1).

Control chest X-ray analysis on day 4 confirmed the correct placement of the plates (Fig. 3). Postoperative pain analysis on day 5 indicated a substantial relief from pain discomfort (VAS pain score of 1).

The total hospitalization was 6 days. Follow-up at 3, 6, 12, and 23 weeks and 11 months, via outpatient clinic

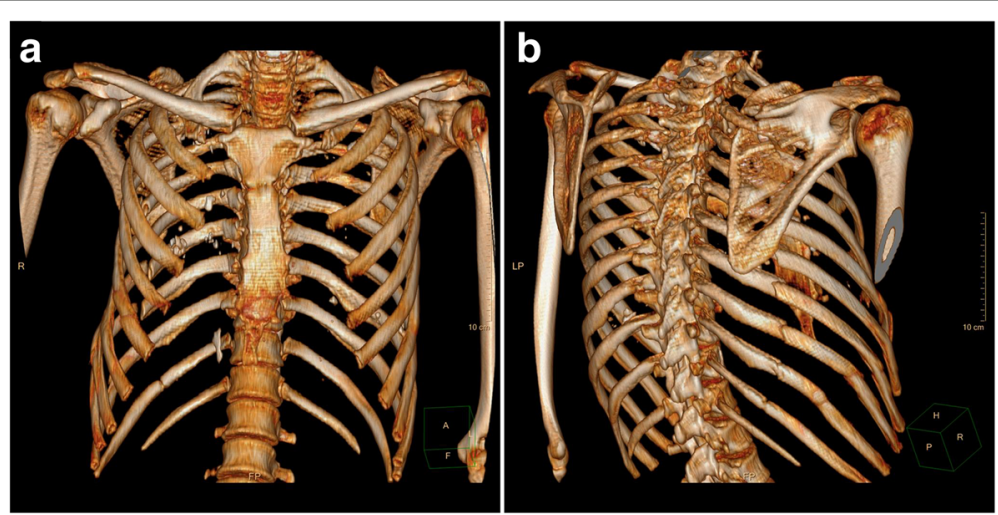

Fig. 1 Preoperative three-dimensional reconstruction of the injuries from computed tomographic imaging. Three-dimensional chest computed tomography (a) anterior and (b) posterior reconstructions in a 41-year-old man who sustained fractures to ribs $5-11$ on the right posterior side as a result of a traffic accident 


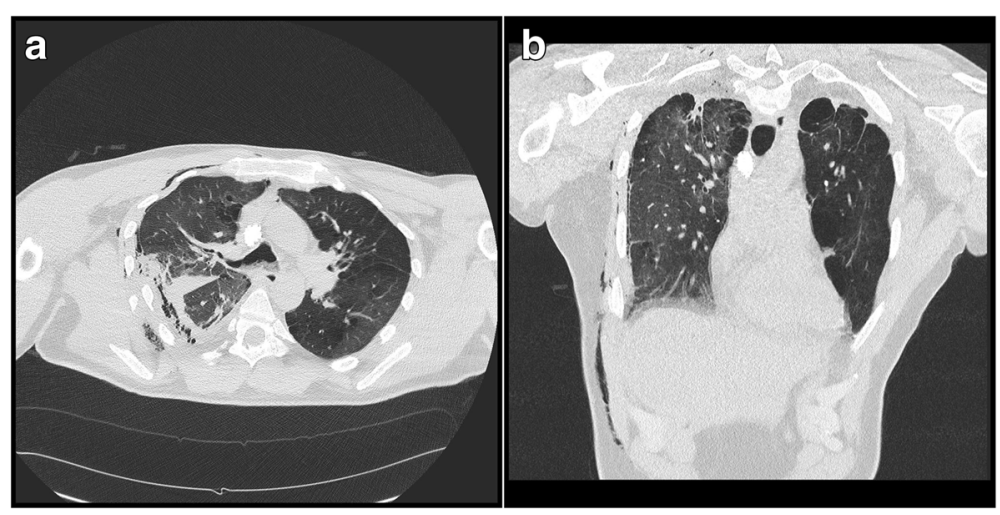

Fig. 2 Preoperative computed tomography of the chest. Axial (a) and anterior (b) computed tomographic imaging indicating pulmonary contusion

visits and phone contact, confirmed a complete physical and mental recovery with no residual symptoms (Fig. 4). The patient reported that he was able to participate in work after 6 weeks and that he had quit smoking since the accident.

\section{Discussion and conclusions}

This case report describes a novel and significant development in emergency medicine in the Republic of Macedonia. Multiple rib fractures resulting from blunt thoracic trauma are commonly treated through conservative means for socioeconomic reasons and because of limited health insurance coverage $[1,2]$. To this end, the successful management of multiple rib fractures based on thoracotomy and surgical fixation is unique to our country.

Developing countries struggle to keep pace with the ever-evolving medical technology and practice guidelines $[11,12]$. In the Republic of Macedonia, market reforms and public incentives have been in place to improve the efficiency and quality of primary health care since the fall of former Yugoslavia [13]. However, despite these measures, emergency and trauma medicine is poorly established [1]. Shared efforts and infrastructure across public and private sectors can help to promote advanced clinical practice and innovation in medical science.

As a consequence of the financial limitations and lack of resources, cases of multiple rib fractures are frequently treated conservatively in developing countries, despite the contraindications $[5,14,15]$. However, increasing numbers of multiple rib fractures correlate with pulmonary morbidity and mortality; patients who sustain fractures of six or more ribs are at significant risk for death resulting from causes (un)related to the rib fractures [16]. Therefore, the ideal clinical approach should be determined according to the severity of the rib fractures $[4,5,7]$. To this end, surgical fixation is currently the cornerstone of treatment for multiple rib fractures because it offers better postoperative pulmonary function, quicker verticalization and mobilization, and a higher quality of life $[8,9,17,18]$.

In light of the discussion above, this report presents a rare case of successful surgical fixation in the management of multiple rib fractures in a developed country that follows recent international recommendations and clinical practice guidelines [5]. Different methods [19] exist for surgical rib fixation, such as intramedullary nails [20], absorbable plating [21], Judet struts [22], Kirschner wires

Table 1 Intra- and postoperative respiratory parameters after surgical rib fixation following a blunt thoracic trauma

\begin{tabular}{|c|c|c|c|c|}
\hline & Day 0 & Day 1 & Day 2 & Day 3 \\
\hline Procedure & $\begin{array}{l}\text { Surgery/patient on continuous mechanical } \\
\text { ventilation support }\end{array}$ & Patient extubated & Arterial line removed & Initial mobilization \\
\hline $\mathrm{SpO}_{2}, \%$ & 97 & 94 & 96 & 95 \\
\hline Nasal oxygen support, L/min & $\mathrm{FiO}_{2} 45 \%^{\mathrm{a}}$ & 4 to 6 & 0 to 4 & 0 \\
\hline Arterial saturation $\mathrm{O}_{2}, \%$ & 95 & 93 & 90 & $N D^{b}$ \\
\hline $\mathrm{PaO}_{2}, \mathrm{mmHg}$ & 98 & 78 & 63 & $N D^{b}$ \\
\hline $\mathrm{PaCO}_{2}, \mathrm{mmHg}$ & 45 & 38 & 42 & $N D^{b}$ \\
\hline Respiratory rate, breaths/min & 14 & 12 & 15 & 14 \\
\hline
\end{tabular}

Abbreviations: $\mathrm{SpO}_{2}$ Peripheral capillary oxygen saturation, $\mathrm{FiO}_{2}$ Fraction of inspired oxygen, $\mathrm{PaO}_{2}$ Partial pressure of oxygen in arterial blood, $\mathrm{PaCO}_{2}$ Partial pressure of carbon dioxide in arterial blood

antraoperative oxygen support

${ }^{\mathrm{b}} \mathrm{ND}$ Not determined. Arterial saturation, $\mathrm{PaO}_{2}$, and $\mathrm{PaCO}_{2}$ could not be determined in the absence of an arterial line 


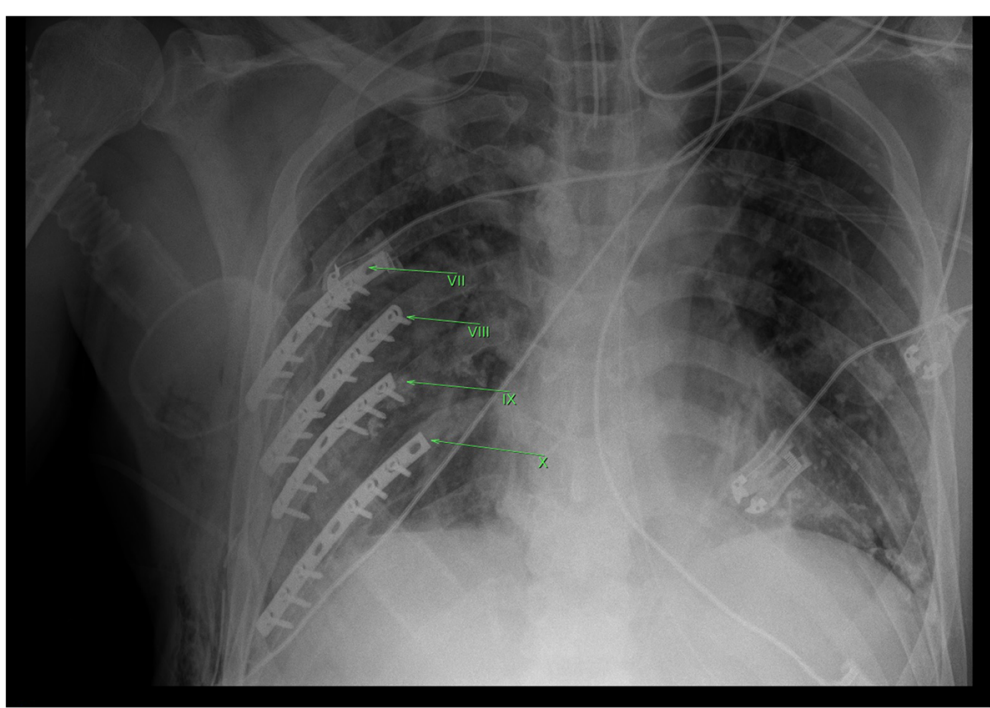

Fig. 3 Postoperative chest $x$-ray of a patient with multiple rib fractures treated via thoracotomy and plate fixation. X-ray image displays the correct placement of the reconstruction plates and cortical locking screws on ribs 7-10

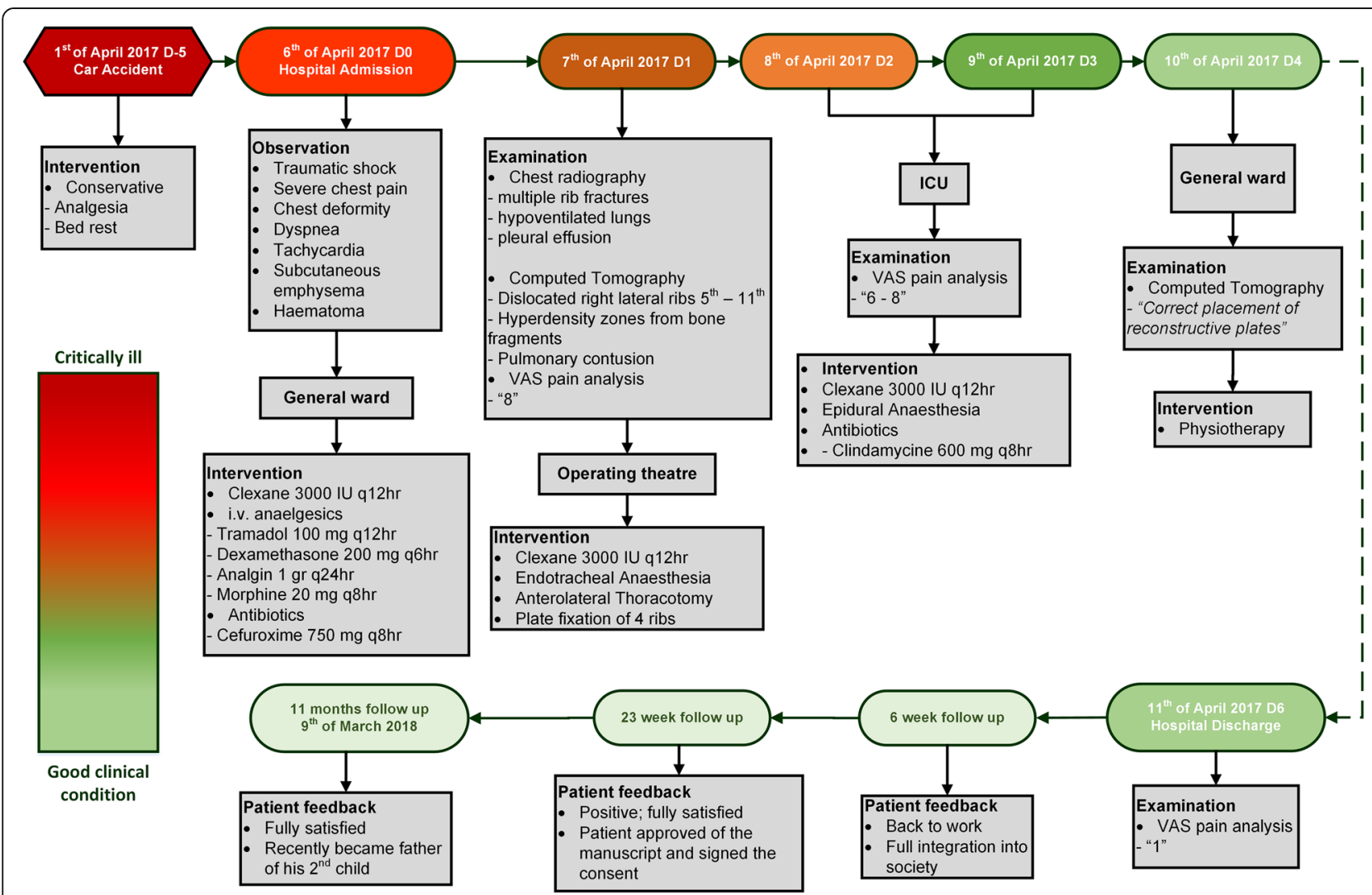

Fig. 4 Hospitalization schedule, detailed treatment plan, and follow-up timeline. Bubbles at top show the specific dates on the timeline, and the colors indicate the clinical condition of the patient according to the color scale bar embedded in the figure. The bigger bubbles indicate key moments on the timeline. Gray boxes summarize the examinations; observations; interventions; medication dosage, schedule, and duration; treatment unit at the hospital; and patient feedback. ICU Intensive care unit, VAS Visual analogue scale 
[23], titanium rib bridges [24], and plating with cortical screws [25]. There is no clear superiority of any of the methods. Nevertheless, the majority of reports describe the use of plating with cortical screws; our surgical approach adhered to the international trend. Indeed, followup examinations pointed to an effective surgical repair of four ribs using the reconstruction plates and successful patient recovery.

We treated the rib fractures using reconstruction plates instead of the precontoured locking plates of the MatrixRIB $^{\mathrm{mm}}$ Fixation System (DePuy Synthes). As mentioned previously, in Macedonia, surgical plating of fractures is relatively rare, with few cases on an annual basis. To maintain cost-effectiveness and applicability to a broader patient population, we prefer the small notch titanium reconstruction plates because of their versatility. These plates can be applied to treat several fracture types, such as fractures of the radius, ulna, fibula, acetabulum, and metatarsals; certain cervical spine fractures; and, as described in this report, rib fractures.

A limitation of the treatment approach presented in this case report was the inability to complete the intended postoperative full-length rehabilitative physical therapy program because the patient resides at a considerable geographical distance from our clinic and has limited means of transportation. It is plausible that an intensive physical therapy regimen, individually tailored for patients recovering from surgery, could have sped up his recovery.

In conclusion, surgical plate fixation using small notch titanium reconstruction plates efficiently stabilized the patient's ribs, mitigated his symptoms, rapidly improved his clinical condition, and promoted a swift reintegration into society. This report highlights a new and promising medical advancement in the Republic of Macedonia and Southeast Europe. Despite the stagnating progress of emergency medicine and limited national healthcare systems, trauma injuries can be treated successfully according to current international medical guidelines to provide the most optimal recovery possible.

\section{Abbreviation}

VAS: Visual analogue scale

\section{Acknowledgements}

We thank Dr. Magdalena Popovska-Cvetkova for her expertise and valuable assistance with the radiographic examinations. We also thank Dr. Gorgi Stavridis for providing information on the number of hospitalizations of trauma patients with multiple rib fractures at the St. Naum Ohridski University Clinic in Skopje, Republic of Macedonia. We are grateful for the extensive writing assistance and academic support provided by Dr. R. Rosalia during the manuscript preparation and revision process.

\section{Availability of data and materials}

The datasets supporting the conclusions of this case report are included within the article.

\section{Authors' contributions}

$\mathrm{KM}$, ES and ZM were responsible for patient care and devising the therapeutic approach. KM and ZM wrote the manuscript with support from DN, who performed the data collection and interpretation of respiratory parameters. All authors read and approved the final manuscript.

Ethics approval and consent to participate

The clinical practice and treatment procedures described in this case report were approved by the ethics committee of the Zan Mitrev Clinic.

\section{Consent for publication}

Written informed consent was obtained from the patient for publication of this case report and any accompanying images. A copy of the written consent is available for review by the Editor-in-Chief of this journal.

\section{Competing interests}

Dr. Zan Mitrev is the hospital director at the Zan Mitrev Clinic. The authors of scientific publications receive financial incentives as a function of the scientific impact of the journal, awarded by the ZMC board. The ZMC scientific officer, R. Rosalia, is exempt from any financial incentive system and attests that the data and patient information described in this report are devoid of any deliberate falsification or other fraudulent practices. The other authors declare that they have no other competing interests.

\section{Publisher's Note}

Springer Nature remains neutral with regard to jurisdictional claims in published maps and institutional affiliations.

\section{Author details}

'Department of Orthopedic Surgery, Zan Mitrev Clinic, Skopje, Republic of Macedonia. ${ }^{2}$ Faculty of Medical Sciences, University Goce Delchev, Shtip, Republic of Macedonia. ${ }^{3}$ Department of Thoracic Surgery, Zan Mitrev Clinic, Skopje, Republic of Macedonia.

Received: 28 December 2017 Accepted: 7 April 2018

Published online: 29 May 2018

\section{References}

1. Nicks B, Spasov M, Watkins C. The state and future of emergency medicine in Macedonia. World J Emerg Med. 2016;7(4):245-9.

2. Milevska Kostova N, Chichevalieva S, Ponce NA, van Ginneken E, Winkelmann J. The former Yugoslav Republic of Macedonia: health system review. Health Syst Transit. 2017;19(3):1-160.

3. Road Safety Status in the former Yugoslav Republic of Macedonia. http:// www.who.int/violence_injury_prevention/road_safety_status/2015/country_ profiles/The_Former_Yugoslav_Republic_of_Macedonia.pdf?ua=1. Accessed 12 Jan 2017.

4. de Moya M, Nirula R, Biffl W. Rib fixation: Who, What, When? Trauma Surgery \& Acute Care Open. 2017;2(1).

5. Pieracci FM, Majercik S, Ali-Osman F, Ang D, Doben A, Edwards JG, French B, Gasparri M, Marasco S, Minshall C, et al. Consensus statement: Surgical stabilization of rib fractures rib fracture colloquium clinical practice guidelines. Injury. 2017;48(2):307-21.

6. Witt $C E$, Bulger EM. Comprehensive approach to the management of the patient with multiple rib fractures: a review and introduction of a bundled rib fracture management protocol. Trauma Surgery \& Acute Care Open. 2017;2(1).

7. Platz JJ, Fabricant L, Norotsky M. Thoracic trauma: injuries, evaluation, and treatment. Surg Clin North Am. 2017:97(4):783-99.

8. Caragounis EC, Fagevik Olsen M, Pazooki D, Granhed H. Surgical treatment of multiple rib fractures and flail chest in trauma: a one-year follow-up study. World J Emerg Surg. 2016;11:27.

9. Slobogean GP, MacPherson CA, Sun T, Pelletier ME, Hameed SM. Surgical fixation vs nonoperative management of flail chest: a meta-analysis. J Am Coll Surg. 2013;216(2):302-11. e1

10. McCormack HM, Horne DJ, Sheather S. Clinical applications of visual analogue scales: a critical review. Psychol Med. 1988;18(4):1007-19.

11. Dupas P. Health behavior in developing countries. Ann Rev Econ. 2011;3(1): $425-49$.

12. Han W. Health care system reforms in developing countries. J Public Health Res. 2012;1(3):199-207. 
13. Nordyke RJ, Peabody JW. Market reforms and public incentives: finding a balance in the Republic of Macedonia. Soc Sci Med (1982). 2002;54(6):939-53.

14. Durnez G. De engel op het eiland: 99 cursiefjes. Antwerp: Manteau; 1983.

15. Dehghan N, de Mestral C, McKee MD, Schemitsch EH, Nathens A. Flail chest injuries: a review of outcomes and treatment practices from the National Trauma Data Bank. J Trauma Acute Care Surg. 2014;76(2):462-8.

16. Flagel BT, Luchette FA, Reed RL, Esposito TJ, Davis KA, Santaniello JM, Gamelli RL. Half-a-dozen ribs: the breakpoint for mortality. Surgery. 2005; 138(4):717-23. discussion 723-725

17. Tanaka H, Yukioka T, Yamaguti Y, Shimizu S, Goto H, Matsuda H, Shimazaki S. Surgical stabilization of internal pneumatic stabilization? A prospective randomized study of management of severe flail chest patients. J Trauma. 2002;52(4):727-32. discussion 732

18. Granetzny A, Abd El-Aal M, Emam E, Shalaby A, Boseila A. Surgical versus conservative treatment of flail chest: evaluation of the pulmonary status. Interact Cardiovasc Thorac Surg. 2005;4(6):583-7.

19. Fitzpatrick DC, Denard PJ, Phelan D, Long WB, Madey SM, Bottlang M. Operative stabilization of flail chest injuries: review of literature and fixation options. Eur J Trauma Emerg Surg. 2010;36(5):427-33.

20. Tarng YW, Liu YY, Huang FD, Lin HL, Wu TC, Chou YP. The surgical stabilization of multiple rib fractures using titanium elastic nail in blunt chest trauma with acute respiratory failure. Surg Endosc. 2016;30:388-95,

21. Vu KC, Skourtis ME, Gong X, Zhou M, Ozaki W, Winn SR. Reduction of rib fractures with a bioresorbable plating system: preliminary observations. J Trauma. 2008;64(5):1264-9.

22. Ahmed Z, Mohyuddin Z. Management of flail chest injury: internal fixation versus endotracheal intubation and ventilation. J Thorac Cardiovasc Surg. 1995;110(6):1676-80.

23. Lee $\mathrm{YH}$, Choi JH, Hwang K, Choi JH. Rib bone graft adjusted to fit the facial asymmetry: a frame structure graft. J Craniofacial Surg. 2015;26(7):2160-2.

24. Coonar AS, Qureshi N, Smith I, Wells FC, Reisberg E, Wihlm JM. A novel titanium rib bridge system for chest wall reconstruction. Ann Thorac Surg. 2009;87(5):e46-8.

25. Sales JR, Ellis TJ, Gillard J, Liu Q, Chen JC, Ham B, Mayberry JC. Biomechanical testing of a novel, minimally invasive rib fracture plating system. J Trauma. 2008;64(5):1270-4.

Ready to submit your research? Choose BMC and benefit from:

- fast, convenient online submission

- thorough peer review by experienced researchers in your field

- rapid publication on acceptance

- support for research data, including large and complex data types

- gold Open Access which fosters wider collaboration and increased citations

- maximum visibility for your research: over $100 \mathrm{M}$ website views per year

At BMC, research is always in progress.

Learn more biomedcentral.com/submissions 